\title{
A TECHNOLOGICAL FRAMEWORK FOR TRANSPARENT E-VOTING SOLUTION IN THE NIGERIAN ELECTORAL SYSTEM
}

\author{
G. O. Uzedhe ${ }^{1, *}$ and J. E. Okhaifoh ${ }^{2}$ \\ 1,2, Electrical \& Electronic Engr. Federal Univ. of Petroleum Resources, EFfurun, Delta State, Nigeria \\ E-mail addresses:1 osmenawin22@yahoo.com, ${ }^{2}$ jokhaifoh@yahoo.com
}

\begin{abstract}
This paper presents the design of a technological framework for electronic voting (E-voting) systems in Nigeria. The traditional voting system with paper ballots used in the Nigeria electoral system is time consuming and in most cases marred with irregularities due to system and/or human errors. These irregularities usually results in inconclusive electoral decisions, violent arguments, and expensive litigations. Certain technologies and recently card readers with biometric authentication have been employed to achieve transparent polls. However, high level frauds still accompany results due to human control of these technological devices and have not generated the required trust resulting in a drastic decrease in voter participation. The framework presented here seeks to combine different e-voting technologies in a way that best suit the Nigeria electoral system in order to build trust and boost participation. The result is an automated polling system that requires minimum supervision with adequate transparency and accuracy of the voting process. The framework showcased how a cost saving real-time electoral procedure can be achieved, with the presentation of precise and accurate results at the end of any election.
\end{abstract}

Keywords: Democracy, Paper ballot, Violence, E-voting, Framework,

\section{INTRODUCTION}

One significant way people express their opinion of choice is through voting. The act of voting is most welcomed in democratic societies and is therefore used as a method through which a society expresses willingness in choice of leadership. Most importantly, voting helps in electoral process of a democratic country in the choice of its government composition. The electoral systems formulate rules that translate individual votes into seats, and therefore affect the representation of society's interests in governance and policy making.

Electoral systems have globally witnessed a tremendous improvement over the last two decades as the need for a reliable electoral system keeps growing. This need is due to perceived electoral fraud that always leads to disputed election results; for instance, the disputed 2000 US presidential election results [1], the disputed 2007 general election in Nigeria which led to several litigations to challenge the outcome of the elections at different levels across the country [2], the violent and legal dispute that ensued after the 2011elections in Nigeria. These challenges have led to electoral reforms; delivering new electoral policies, amendment of national constitutions and the provision of adequate facilities to implement new electoral technologies.

Recently, there is an urge by most nations to move from the traditional voting processes to the use of technology $[3,4]$ in various political systems. The technology sought the most is the Electronic Voting Systems (EVS) which provides a growing number of advantages, comparable performance with more preference over other technologies [5, 6]. Today's digital electronics technology have open more access to the use of EVSs in several national electoral processes due to its high accuracy, precision, flexibility $[7,8]$ and support for technology integration, and the ability to operate with less human intervention. However, several criticisms have emanated to challenge the credibility of such technology especially as it apply to security issues [8, $10,11,12,13]$ and the power of incumbency to influence the manufacture, distribution, and use of such devices. That notwithstanding, the level of human introduced errors and fraudulent tendencies in most other manually operated electoral systems $[8$, 
$14,15]$ have increase nations confidence on these EVS technologies.

Most national or state wide elections conducted in a number of democracies in Africa have ended up in violence [16]. In Nigeria this violence is a direct result of mistrust, suspicion, lack of confidence in the existing paper balloting process. However, in the just concluded 2015 national elections, the Independent National Electoral Commission (INEC), as the Nigeria electoral umpire, introduced the use of biometric card reader for the verification of permanent voter's identification card. The decision, seem to be rashly made and did not went through due process of legislation for the use of such devices [3] in critical national elections. It however, gained a wide acceptance and seems to have served to increase voters' confidence in the electoral process. To face reality, Nigeria as a multi-cultural, multi-religious, multi-ethnic, and regionally diversified state, will always have trust and confidence related problems with the existing manual electoral system. As it stands no amount of legislation and physical security improvement can erase these facts, unless the country looks towards a trusted technology that will serve as an unbiased process and build the people's confidence.

In the Nigeria electoral system, voters are presented with multiple-party multiple-candidate ballot papers to thumb print for a choice candidate. The process of accreditation of voters has been a serious challenge leading to various electoral frauds. To make the situation worst is the fact that multiple thumb printed ballots by a single voter $[17,18,19]$ cannot be verified after the polls. The slogan "One Man One Vote" has been largely sung by government after government yet its implementation at the poll is always flawed. In the 2015 National elections, the introduction of the biometric card readers did not totally eliminate multiple voting. The verification process also made it possible for dishonest electoral administration officers to permit fraudulent voting. Credibility and transparency at the polling booth build voters' confidence, and this is what the country needs to sustain its democracy. Therefore, this paper develops a conceptual framework for credible and confident electronic democracy with cognizance to the biometric verification card readers recently introduced by INEC.

\section{NATIONS WITH E-VOTING EXPERIENCE}

Every electoral system looks forward to executing a transparent process that satisfies the expectations of the electorates, political parties, electoral candidates, and observers. To achieve this transparency, the electoral process must be trusted and reliable. Such factors are driving democratic nations all over the world into the use of more satisfactory technologies for the execution of electoral processes. While some nations have legally adopted the use of EVS, a number of others are experimenting with e-voting, and a few others are considering their use. Some however, have out rightly rejected the use of e-voting for certain reasons. The following sub-sections take a brief look at countries with some experiences of EVS.

\subsection{Nations with Full EVS}

A number of democracies have fully adopted the use of different e-voting technologies. This decision is a factor of trust and confidence resulting from the long use of EVS in addition to the numerous advantages the technologies provide. Australia, Canada, France, and Japan are legally using a combination of voting machines and internet voting systems in their electoral processes, while Austria, Estonia, and Switzerland adopt the use internet voting system, Brazil, India, Kazakhstan, Peru, Russia, USA, UAE, and Venezuela are legally using voting machines options[4, 20].

\subsection{Nations that rejected EVS}

In some countries, the use of electronic voting has been voted down for certain reasons. These agitations against the use of EVS are largely due to suspicions and mistrust from opposition political parties as well as the fear of voter's insecurity. Germany, Ireland, and Netherland have rejected the use of electronic voting majorly due to opposition pressure without concrete and holistic evaluation of these systems [21]. The present discontinuity of e-voting systems in these countries was based on test carried out on a single evoting system, the NEDAP electronic voting systems developed by a Dutch company in the eighties [22].In Ireland, the opposition complained of the accuracy and secrecy of the e-voting machine which subsequently led to their stoppage for elections beginning from 2004 even though they were not adequately tested $[23,21,20]$. Netherland has questioned the use of electronic voting earlier in the late 90s [24, 25].They complained of the secrecy and possibility of results verification with the electronic systems. Taking lead from the Ireland termination of the e-voting systems, they successfully put a stop to the use of EVS in 2007 [22]. In Germany, the use of electronic voting has been put on hold since 2005 
resulting from law suit from two voters. These voters only questioned the constitutional use of e-voting systems in Germany. This led to the ruling by the German Constitutional Court that the use of e-voting systems is unconstitutional [26, 27]. The court however did not rule out the possible use of EVS in future German elections.

Paraguay since 2008 has upheld the use of paper ballot as against the use of electronic voting previously use. This decision was due to opposition pressure that led to an opinion poll by the supreme electoral court of justice in Paraguay [20]. The results of the poll see an end to the use of EVS in that country without concrete reasons. United Kingdom experimented with e-voting in 2002, 2003 and 2007 and has since then abandoned the use of EVS due to security complains from opposition parties $[28,29]$.

\subsection{Nations Considering and Experimenting on EVS}

Successes recorded in the use of EVS by several democracies and the advantage of getting more people involved in the electoral process have made more countries to consider its use while some are already experimenting on the use of EVS as a better alternative to other voting systems. Argentina, Belarus, Chile, Czech Republic, Finland, Italy, Latvia, Mexico, Nepal, Poland, Romania, Spain, South Korea, Venezuela, Costa Rica, and a lot of others in Asia, South America, and Europe [4] are presently experimenting on the use of EVS at various levels of their national elections. In Africa, Ghana and Nigeria $[30,31,32,33]$ are considering and planning the use of EVS, South Africa currently debate its use [34, 35], while Namibia has recently and successfully conducted its first electronic voting elections [36]. There are calls in Zambia and Zimbabwe to apply evoting for its coming election following successes from Namibia [37, 38, 39]. Democratic elections in Africa countries are very volatile and vulnerable. This is particularly due to high level of mistrust among political parties whose formations are always bent towards ethnical and religious differences. The electronic voting system will serve to bridge the trust gap that has ever existed. The Namibian experience has shown that the application of EVS in Africa democracies is the right direction and should be followed by other countries. All that is needed is to develop the right framework for adoption and application of EVS with all parties and interest groups involved.

\section{WHY USE E-VOTING IN NIGERIA?}

Nigeria is a peculiar country with so many diversified cultural believes, religious affiliation, and ethnic backgrounds. Literacy level is also separated within divides of believes, affiliations, and economic sidelines. Notwithstanding, Nigeria is politically divided into regions that poses in most cases a mixture of these factors. Notable among these divisions is the north and south dichotomy that exist since the colonial era. The electoral processes in the country are heavily affected by these factors and bring a number of challenges to the conduct of credible elections in almost every level of governance. Some of these challenges are electoral right on franchise, regionalization of political positions, electoral fraud, and high tendencies to election violence.

\subsection{Right on franchise}

A general challenge in every democratic society is the right of who can be voted for and who can vote. Most systems use age and literacy level to determine those qualified to be voted for $[40,41]$, while age alone is use to determine those eligible to vote[42, 43]. Nigeria is not an exemption from this; voters must attain age of 18years and above to be eligible for a franchise irrespective of literacy level, health status, and religious affiliation. This seems to be very appealing especially as it cover persons from all aspect of life. It also worked very well for manual electoral processes. The handicapped, old people and the illiterates can just be lead blindly to thumb print the ballot (vote) in most cases against their will. They may have little or no knowledge of the candidate they are voting for. Today's society is growing smarter with even the younger people having access to more education and information. So, the question is 'why age 18 for a franchise? That someone is physically matured does not imply the ability to make good decisions and right judgments. Over time, illiteracy have always result to poor voting process usually through time wasting, invalidated votes and voting for the unintended candidates.

In our own opinion, the age limitation is not just enough to determine the franchise right of voters. As we gradually slope into an era of modern electronics voting systems, literacy is an important factor not only for the choice of candidates but also to enable the voter go through the voting process. To be able to read and write is at least a good starting point; however voters should be encouraged by legislation to acquire necessary computer literacy prior to election times. This will as well force the government, opposition parties, and concern citizens that will be seeking 
election to various positions to show more commitment to the education of voters. When voters are educated, they are more likely to vote wisely. The time wasting factors at the poll and the tendency of vote swing to the wrong candidate due to invalid vote will be drastically reduced. It is therefore suggested here that the voter's age limit be reviewed downwards and literacy clause be included in the right of franchise to voters in Nigeria.

\subsection{Regionalization of Political Positions}

Regionalization of top federal level of political positions called zoning in Nigeria has become an arguable political distribution method for certain offices. Looking at the regional political planning of the country, zoning seems to place some sort of check and balances in the electoral system. However, when allowed to take root, it will bring about more political divisions as every locality in the regions would want the same style to be adopted for every office thereby breaking the cord of democracy. For true democracy to be attained and sustained, the country must ignore the act of zoning and focus more on the enlightenment and education of the people in matters relating to governance. Using appropriate democratic tools, the right candidate from the people's choice can be place in any office irrespective of the region he/she comes from. Democracy is an act of choice by people and not that of prescription. Zoning will result in selection of candidates, by few individuals, which are then forced on the people against their will. This will produce the wrong results as such candidate tends to fulfill the will of the caucus and ignore the political will of the people.

\subsection{Electoral fraud}

The Nigeria democratic system has gone through series of tests and has barely survived through sacrifices made by candidates, political parties and the electorate. The most challenging part of this test is on how to overcome electoral fraud. Electoral fraud in Nigeria democratic system exist in all political levels ranging from result manipulations by corrupt electoral officials to outright intimidation of voters by both party thugs and law enforcement agencies.

Corrupt and biased practices of INEC and its electoral official alone over the years [44] has led to the general believe among the electorate that their vote do not really count. The average Nigerian voter does not trust the credibility of INEC and its official as long as paper ballot is being used. In several occasions, electoral officials allow and even carryout multiple thumb printing of ballots for a candidate or a political party, inflate result figures or even discard original results and replace them with fictitious ones [45]. A second degree source of fraud is that of intimidation of voters by party thugs and corrupt law enforcement agents. These intimidations are not usually to force voters to thumb print for a preferred candidate or party, but rather to scare voters away from the polling stations in order to give room for multiple thumb printing of ballots and possibly result mutilation. Next is the problem of ballot theft [46]. Ballot theft, especially under duress, has been a recurrent fraud in Nigerian elections and in some cases abated by electoral officials and law enforcement agents at the poll. It also occurs in the form of diversion of election materials to unknown destinations. These ballots are thumb printed by a few individuals and somehow, the results from such stolen ballot boxes find their way into INEC office as part of the results. The last of these frauds is that of vote buying that takes place during campaigns and right in the poll during elections [47]. Due to lack of understanding of what the act of governance is, illiteracy and high level of poverty among the electorate, election periods seem to be times of opportunity and not the time of right choices. In this regard, the Nigeria democracy could be referred to as "money democracy", because it is usually those who have more buying power especially offering money during the polls that are likely to win. In our opinion, unless the living standard of the average Nigerian voter is significantly improved, credible elections will be far-fetched.

\subsection{Election violence}

Election violence is a deep rooted problem in the Nigeria democratic system $[47,48]$. In every election year, different forms of predictions about possible violence are made. These predictions are hinged on the lack of trust in the electoral system from previous experiences, and ride on the back of ethnic, religion and regional divides. Even within the same political party, indication of interest to run as a candidate for a position alone can result to violence and have cost lives [49]. Violence during elections and after elections results from lack of trust and transparency in the conduct of election. Though it could also result from other factors such as bias and intentional instigations, lack of trust and non-transparency seem to have played the worst role in building election violence.

Election violence in Nigeria have caused so much loss of lives [50,51,52]. It is therefore imperative to find ways to put an end to the reoccurrence of this societal 
evil. While awareness, education, and adequate legislation can be used as tools to militate against other causes of violence, trust and transparency can be properly tackled by the use of appropriate technology with the right logistics. The Nigeria society has a growing history of trust on the use of technology as exemplified in the acceptance and use of electronic banking systems. Although, the introduction of biometric card readers in the 2015 election did not see through proper legislation on time, its wide acceptance and subsequent use shows that Nigeria voters are in dying need of a system that can be trusted to deliver to them a most credible election.

\section{PROPOSED FRAMEWORK FOR CREDIBLE E- DEMOCRATIC ELECTIONS}

With the recent introduction of biometric card readers, multiple thumb printing was expected to stop in the paper ballot era. This however was not the case and will not likely be the solution in the paper ballot system [32]. Again, with the consciousness that the people votes will not count, fear of being intimidated at the polls and possible election violence that may occur during elections, majority of voters are totally discouraged and as well lack trust in the paper ballot system currently in use. The result is that there is always low participation as observed by low turnout of voters during elections in most parts of the country. To build trust and encourage voters, the proposed framework can be used to synchronize various technologies to accommodate the excesses of the current voting system. These technologies are either internet enabled or non-internet based. No technology at the moment can be claimed to be the most appropriate and sole technology for credible election delivery in Nigeria. This is because there are prevailing issues of poor electricity supply, poor internet connectivity,and lack of access roads to most remote areas. More so, a large part of voter population, especially in the rural areas, is made up of semi-literate or illiterate persons. Hence, election administration, most especially in the rural areas, can be very challenging.

In order to produce an effective and reliable electoral system, acceptable technologies must support both internet voting and standalone electronic voting options. Both of these can be deployed to internet reached environments, while the standalone option must be used in the non-internet reached areas. The use of internet of course gives a number of options to voters. There will be the need to deploy internet enable polling units, and as well enable existing ATM machines for the polls. This will essentially increase participation and boost confidence since most people have come to trust the ATM for daily financial transactions. Internet enabled mobile devices are on the increase and a growing population is being connected. Hence, mobile internet voting is an available and sure way to increase voter participation. To maintain a correlation among these technologies, a proper administration is required.

\subsection{Proposed Election Administrative Framework}

A reliable administrative framework with checks and balances must stand as a backbone for any electoral process. The election administration framework presented here as shown in Figure1 provides a flexible means to support technology for election administration. The administrative framework consists of two levels of operation that deals with the allocation of electoral materials and personnel as well as results collation. The National Allocation and Collation Unit oversee electoral activities in all states by allocating material and personnel, and receive all collated results. It is also responsible for initiating (starting) and ensuring that all elections are carried out to conclusion (i.e. ended). Hence all election results are received at the national level before publication. At the state level, the State Allocation and Collation Unit will directly allocate materials and personnel to the various voting units. Elections are carried out at the state level which ensures compliance with the national level regulation.

In order to keep the allocation and collation department in check, there is the National and State Level Verification department through which allocations and election returns will be verify for balances before results can be published. The verification department also serves as a check point for voters to individually verify their vote for any possible manipulations after casting their votes. Due to the sensitivity of the verification department, there is the need for cross verification between the national and state levels as well as the Election Observation and Monitoring Unit. The Election Observation and Monitoring Unit comprise of both internal and external electoral observation and monitoring groups. This unit directly monitors and observes elections on the field, state, and national results collation processes. The field includes all voting units utilizing various technologies deployed for the polls. 


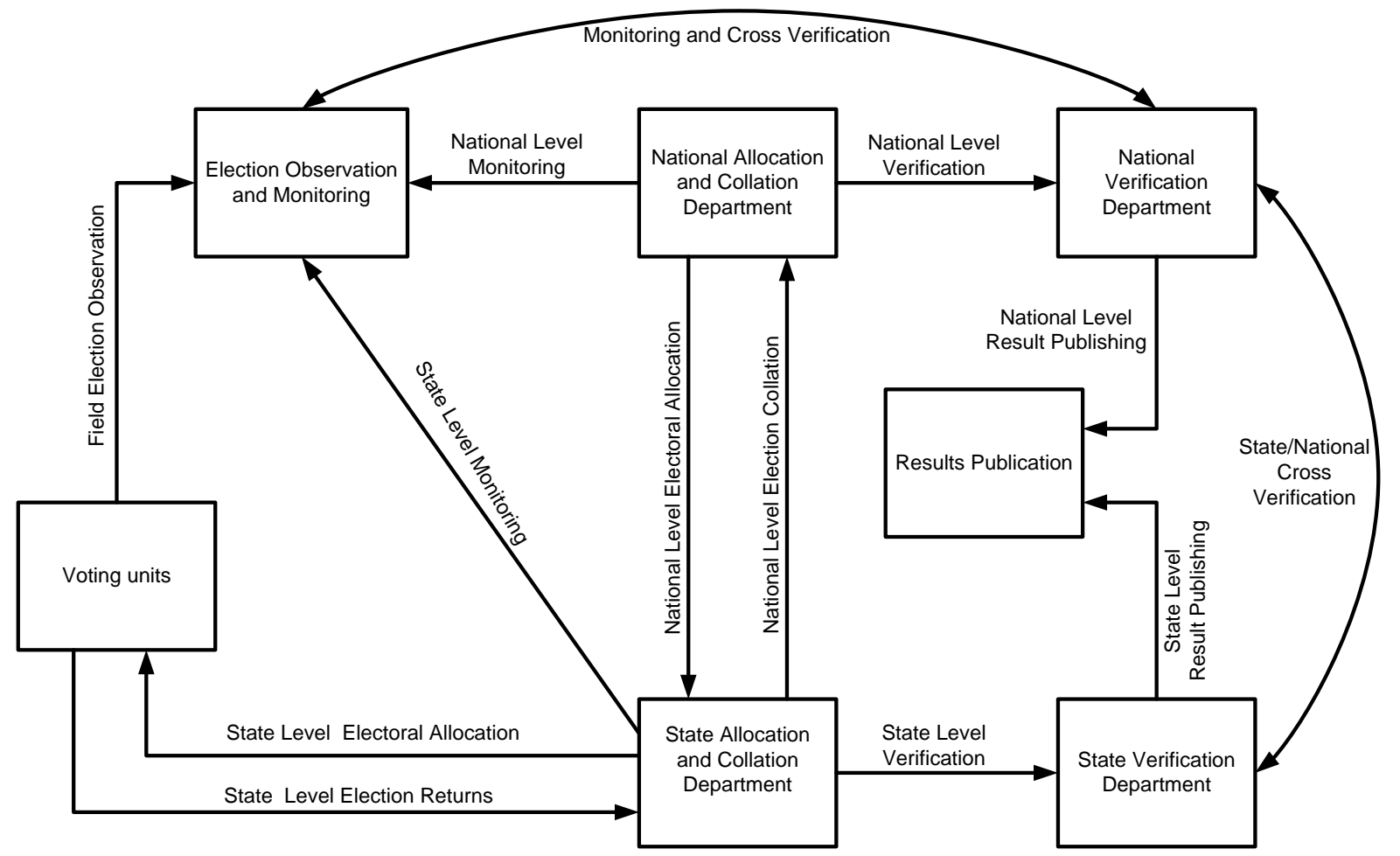

Figure 1: Election Administrative Framework

To build more trust in the electoral system, transparency in the administrative process must be ensured. This will be rightly achieved by the use of appropriate technologies. Wireless transmission of electoral information using different media will serve well. The wireless technology however, must be secure, accessible and trusted. It must provide room for everybody to have access to required public information. The most prevalent of these wireless technologies at the moment, that meet the criteria, are the internet and global system for mobile communication (GSM). And to a better advantage, both technologies can be interconnected for information interchange. This will provide real time election monitoring and greatly augment physical checks for verifications. The use of these technologies for electoral administration will create the necessary flexibility that enables elections to be handled in a more acceptable way due to real time accessibility. Elections are monitored directly and much more closely, with high leverage on these technologies for cost reduction.

\subsection{Voter Classification}

Generally, voting in national or state-wide elections takes place in a wide geographical area of land. This land area is of course made up of different types of living environments with the voters having varying degree of educational background, health related challenges and different access to technology. Therefore, for effective use of this technological framework for elections, voters are classified here as:

(i) Living in remote area or urban area

(ii) Living outside internet accessible area or in an internet accessible area.

(iii) The internet accessible voter is an illiterate or a literate person.

(iv) A disabled or able person.

Remote area refers to places that are not easily accessible and probably not internet connected. Voters who reside in remote areas are left with the option of voting in stand-alone voting machines. It does not really matter here whether the voter is literate or not, able or disabled. Disabled persons however, can be assisted under special arrangement to participate in the process. This could be done by the provision of a mobile stand-alone polling station specifically designed for the disabled. The accessible voter on the other hand is internet reached but may be literate or illiterate. The illiterate urbane dweller can be made to vote with stand-alone voting machines stationed at different polling points. However, literate urbane voter has varieties of voting options. These options includes the use of internet enabled automated polling stations, Automatic Teller Machine (ATM) internet enabled voting system, mobile internet voting, and of course, the use of stand-alone voting machines. This classification as depicted in 
Figure 2, provides a good consideration for the distribution of polling technology devices.

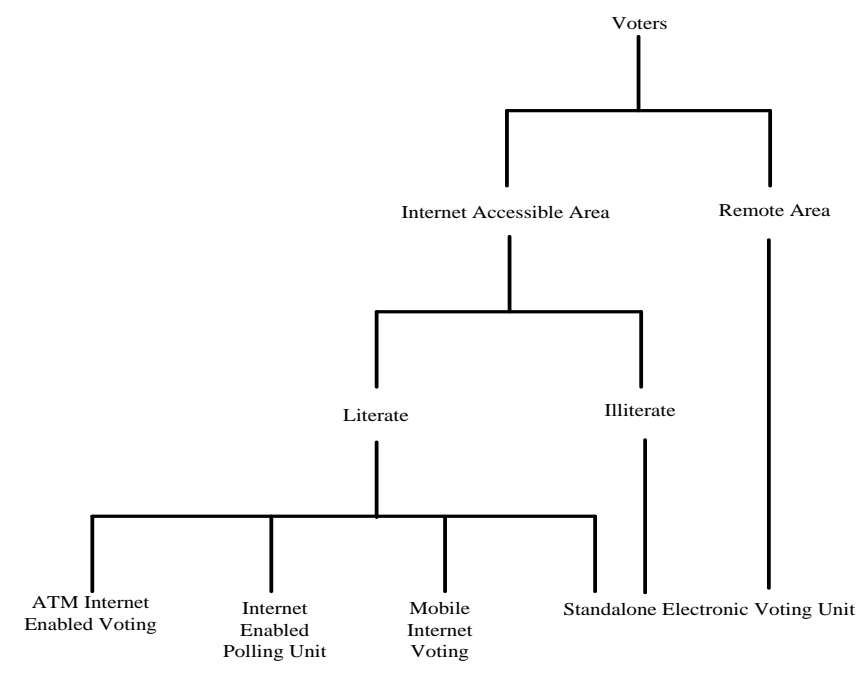

Figure 2: Voter Classification

\subsection{Internet and Stand-alone polling systems}

Polling systems are the most important part of any electoral process and must be generally acceptable by the voter population. Today, electronic devices have made a large impart in every aspect of our life and have been accepted for everyday communication, business transaction, etc. Therefore, the acceptance of electronic devices for the poll in the form of standalone or internet enabled electronic system will not pose any significant challenges. However, challenges could arise if the formulations of these devices are not open enough. The development of these devices (both in hardware and software terms) must be transparent and accessible by concerned agencies.

The internet opens a wide range of voting options and will generally encourage wide participation especially when mobile applications are deployed. The internet may have its own problems such as network downtimes and data security, but can be reliable enough for any electoral process. Therefore, the development of internet based electronic voting systems should take care of these challenges right from design. For example, each internet polling unit could be equipped with enough memory to hold data and the ability to be used as a standalone system in prolonged network downtimes. The standalone polling units on the other hand, are very good voting option for non-internet reached and illiterate voters. These devices must therefore be developed and build in such a way that voter participation could be encouraged. These devices must not be too large and complex to setup, and should be provided in good numbers. This will avoid long waiting in queues, encouraging voter participation.

Other issues that should be addressed are the ease of use, and adaptability. The voter must not find it difficult to understand the voting process. The electronic devices should be provided with a very simple interface for clear information display through text and graphics. This simplicity will reduce swing voting and cost of voter education for the polls. Again, as these devices are going to be used in different environments, they must be made to adapt to the possible different situations such as whether conditions and power outages.

\subsection{Results and Information collation Process}

Result collation is a very crucial part of every election and must therefore be handled with no levity. With the use of this technology framework, result collation process will be faster, real-time, error free, and at reduced cost. Figure 3 shows how election administration information can be coordinated using these technologies. In this framework, the State Level Information Control is responsible for election results and related information collation. The National Level Information Control coordinates the different states results collation. With the existence of the internet and GSM networks, raw results and other vital information can be received at any point depending on the access level. The internet voting option is the most accessible and has direct link to all administrative levels. With the internet, votes are real-time and can be view on progress. The SMS instant message option on the other hand, serves as an automatic report link for the standalone voting systems in areas deemed as non-internet accessible but with GSM network coverage. Hence, the standalone systems are expected to carry an in-build GSM module for instant reporting. The SMS reports are summary of the votes from a specified unit and are not expected to give details of the voting process. The election details in a unit are received only on the submission of the standalone system's hardware, from where the information can be read. In the absence of the GSM network, the standalone system stores the report and transmits it upon the reception of GSM network signal during its submission. This communication transparency ensures that the electoral process is open and builds the required trust 


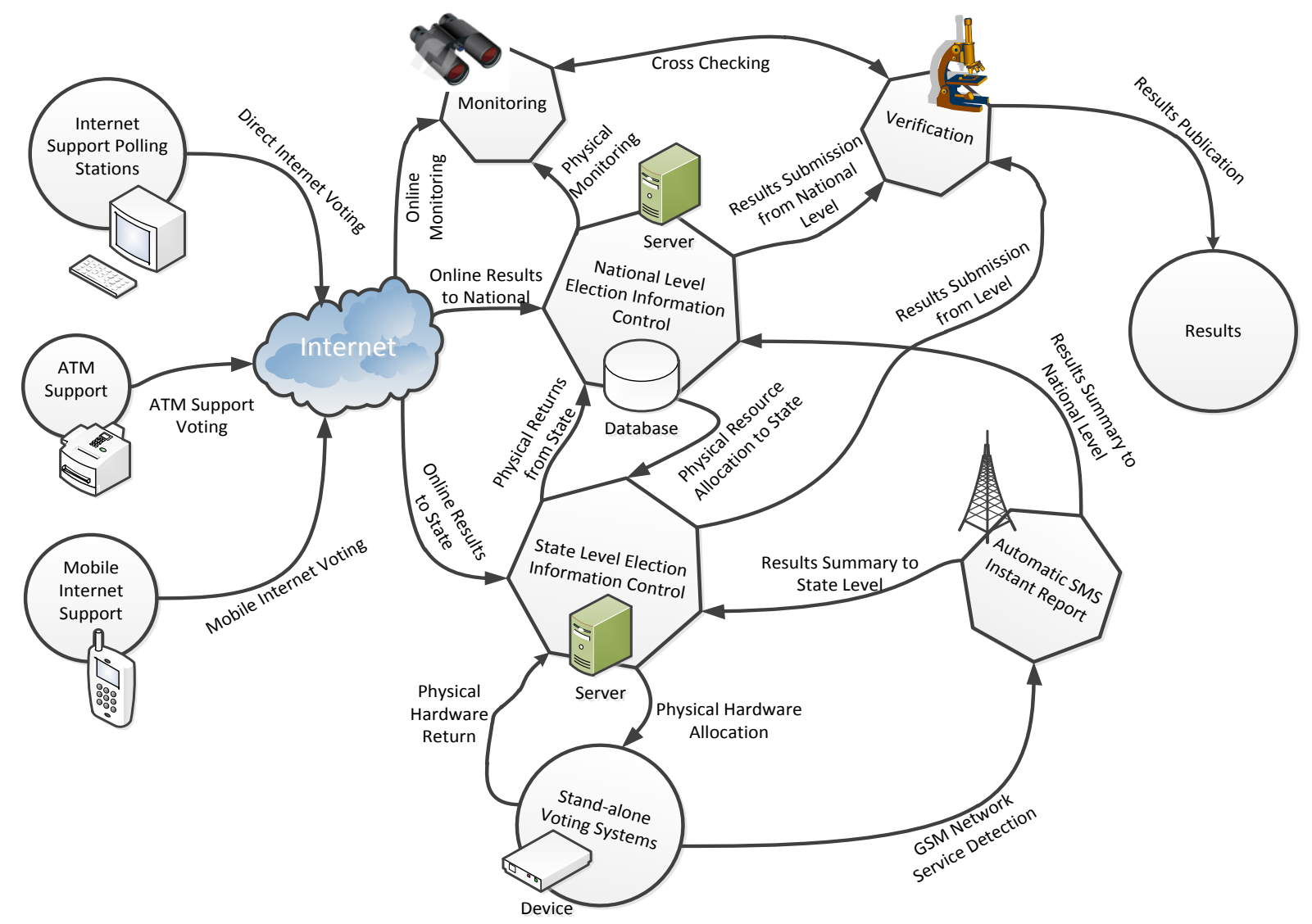

Figure 3: Election Administration Information Control

The use of these technologies will create a hard to break cord in election report by fraudulent officials. This is because the electoral official is not aware of what reports are submitted and when they are being submitted.

\subsection{Security and Privacy}

Security of ballots and voter's information is a vital topic in the use of electronics voting systems. Voter privacy must also be ensured since votes are to be cast in secret. The internet options are prone to cyberattacks while the standalone systems are prone to theft and other physical attacks. Measures must therefore be put in place from conception to secure these devices from any possible attack. While using hard architectures [53,54] and difficult encryption techniques to secure votes and voter's information in the internet option, launching counter cyber-attack against any security threat may also be required. In the standalone option, the use of security personnel is required in addition to the use of proof-casing, electronic authentication system (password and biometrics), and self-destructive software algorithms that will render a device memory content useless upon unauthorized access.

\section{CONCLUSION, RECOMMENDATION AND PLAN FOR FUTURE RESEARCH}

Transparency in an electoral process builds trust and confidence of political parties and voters alike. The use of manual voting systems such as the paper ballot have not satisfy this need due to human errors and fraud, and are also usually very expensive to run. To reduce cost of election administration as well as eliminate human error and fraud from the electoral system, different nations have turned to the use of technology. Today, the electronic technology is offering different voting solution at a constant reducing cost. Though the use of a particular electronic voting solution may not fully satisfy the need of any nation, using an appropriate electronic voting framework will ensure transparency. This paper has presented a technology framework for the Nigeria electoral system. The framework combines the use of internet enabled and standalone electronic voting devices for the polls. With the current growth in the use of internet and GSM network technologies, the adoption of such framework as this will drastically reduce electoral cost, increase participation and reduce or even eliminate electoral violence in Nigeria. The recent use of biometric devices is a commendable step but future elections should feature the use of new 
electronic voting processes that are tailored specifically for the Nigeria environment. The development of such devices and voting processes therefore form the basis of future researches in the Nigeria electoral system.

\section{REFERENCES}

[1] D. Bal, Up by 930, Bush Side Assails Recount", Washington Post, November 19, 2000.

[2] O. V. Ojo, "Turbulent Election History: An Appraisal of Precipitating Factors in Nigeria", International Journal of Politics and Good Governance Volume 5, No. 5.2 Quarter II 2014,

[3] Democracy Reporting International, "Support for Electoral Report in Pakistan", [online]. Available: http://pakistan.democracy-reporting.org/ [Accessed: 18/07/2015]

[4] E-Voting, "Countries with e-voting projects", [online]. Available: http://aceproject.org/aceen/focus/e-voting/countries [Accessed: 01/12/2015].

[5] S. P. Everett, K. K. Greene, M. D. Byrne, D. S. Wallach, K. Derr, D. Sandler, and T. Torous, "Electronic Voting Machines versus Traditional Methods: Improved Preference, Similar Performance", CHI 2008 Proceedings-Measuring, Business, and Voting. Florence, Italy, April 5-10, 2008.

[6] E-Politics, "The Internet has returned politics to the grass roots", [online]. Available: http://csc1102epolitics.blogspot.com/2012/01/advantages-anddisadvantages [Accessed:08/06/2015].

[7] Tsun-Shao Chen, "Electronic Voting", [online]. Available:https://files.nyu.edu/tsc223/public/Elect ronicVoting.pdf, [Accessed: 18/07/2015]

[8] Y. Asiamah, "Electronic Voting in Ghana: Is It The Solution To Ghana's Perceive Electoral Challenges After Biometric Registration?", Journal of Information Engineering and Applications, Vol. 3, No. 1, 2013.

[9] T. Kohno, A. Stubblefield, A. D. Rubin, and D. S. Wallach, "Analysis of an Electronic Voting System", IEEE Symposium on Security and Privacy 2004, IEEE Computer Society Press, May 2004.

[10] S. Wolchok, E. Wustrow, J. A. Halderman, H. K. Prasad, A. Kankipati, S. K. Sakhamuri, V. Yagati, and R. Gonggrijp, "Security Analysis of India's Electronic Voting Machines", CCS'10, Chicago, Illinois, USA, October 4-8, 2010.

[11] A. M. Keller, D. Mertz, J. L. Hall and A. Urken, "Privacy Issues in an Electronic Voting Machine", [Online].

Available:gnosis.cx/publish/voting/privacyelectronic-voting.pdf, [Accessed: 18/07/2015]

[12] The Carter Center, "Automated Voting and Election Observation", Summary of Proceedings, March 1718, 2005.

[13] Jonathan Bannet et al, "Hack-a-Vote: Demonstrating Security Issues with Electronic Voting Systems",
IEEE Security \& Privacy, IEEE Computer Society, 1540-7993, January/February 2004.

[14] D. P. Kitlan and R. C. Joseph, "An Examination of Factors Affecting Multilevel E-Voting", [Online]. Avaible: http://www.nedsi.org/proc/ 2008/ proc/p07102002.pdf, [Accessed: 18/07/2015].

[15] M. Achieng and E. Ruhode, "The Adoption and Challenges of Electronic Voting Technologies within the South African Context", International Journal of Managing Information Technology (IJMIT), Vol.5, No.4, November 2013.

[16] "Electoral Violence in Africa", The Nordic Africa Institute, Policy Notes 2012/2013.

[17] “Policy Briefing: Lessons from Nigeria's 2011 Elections", International Crisis Group Working to Prevent Conflict Worldwide, [Online]. Available: http://www.crisisgroup.org/ /media/Files/africa /west-africa/nigeria/B79 Nigerians Elections --Reversing the Degeneration.pdf, [Accessed: 09/12/2015].

[18] "Nigeria Decides: Video exposes INEC officials colluding with PDP to rig elections", Premium Times March 30, 2015.

[19] C. Nwangwu, "Biometric Voting Technology and the 2015 General Elections in Nigeria", Department of Political Science, University of Nigeria, Nsukka,

[20] J. B. Esteve, B. Goldsmith and J. Turner, "International Experience with E-voting: Norwegian E-vote Project", International Foundation for Electoral Systems, 1850 K Street, NW, Fifth Floor Washington, DC 20006, 2012.

[21] K. Niemoller, "Appendix 2K: Experience with Voting Machines in the Netherlands and Germany", THE POLICY INSTITUTE, TRINITY COLLEGE DUBLIN, [Online]. Available: http://www.umic.pt/images/stories/publicacoes1/ Appendix\%202K.pdf, [Accessed: 20/12/2015].

[22] B. Goldsmith and H. Ruthrauff, "Implementing and Overseeing Electronic Voting and Counting Technologies: Case Study Report on Electronic Voting in the Netherlands", United States Agency for International Development (USAID) under Award No. DFD-A-00-08-00350-00.

[23] J.J van Hoof, J. F. Gosselt, and M. D.T. de Jong, "The Reliability and Usability of the NEDAP Voting Machine: A Pilot Study", University of Twente Faculty of Behavioural Sciences Department of Technical and Professional Communication, January 2007.

[24] B. Jacobs and W. Pieters, "Electronic Voting in the Netherlands: from early Adoption to early Abolishment", Foundations of Security Analysis and Design V: FOSAD 2007/2008/2009 Tutorial Lectures. Springer LNCS 5705, p. 121-144, 2009. 
[25] The National Democratic Institute, "Netherlands: Concerns about Electronic Voting", [Online].Available: https://www.ndi.org/e-votingguide/netherlands-CS/concerns-about-e-voting, [Accessed: 20/12/2015].

[26] Dr. Boehl, "The Future use of voting machines after the decision of the Constitutional Court", Minutes of meetings, Federal Ministry of the Interior Unit VI 5 Ref.: VI 5121 115/11 Berlin, Tuesday, 02/03/2010.

[27] The National Democratic Institute, "The Constitutionality of Electronic Voting in Germany", [Online]. Available: https://www.ndi.org/e-votingguide/examples/constitutionality-of-electronicvoting-germany, [Accessed: 20/12/2015].

[28] S. Kumar, E. Waliam., "Analysis of Electronic Voting System in Various Countries", International Journal on Computer Science and Engineering (IJCSE), Vol. 3 No. 5 May 2011.

[29] A. Charlton, "Election 2015: Why can't we vote online?", International Business Times, April 17, 2015.

[30] A. Yeboah, "Electronic Voting in Ghana: Is It The Solution To Ghana's Perceived Electoral Challenges After Biometric Registration?", Journal of Information Engineering and Applications, Vol.3, No.1, 2013.

[31] M. 0. Yinyeh , K. A. Gbolagade, "Overview of Biometric Electronic Voting System in Ghana", International Journal of Advanced Research in Computer Science and Software Engineering, Volume 3, Issue 7, July 2013.

[32] P. O. Omolaye, P. Daniel, and A. O. Orifa, "Systemic Evaluation of Semi-Electronic Voting System adopted in Nigeria 2015 General Elections", American Journal of Information Systems, 2015, Vol. 3, No. 1, 15-21.

[33] S. Ahmada, S. A. Abdullahb and R.Arshadc, "Issues and Challenges of Transition to e-Voting Technology in Nigeria", Public Policy and Administration Research, Vol.5, No.4, 2015,

[34] A. Krishnan, "Electronic voting: A platform for electoral change?", People's Assembly April 30, 2014.

[35] T. Ngubeni, "E-voting in SA: 'Not so fast'", Web ICT Management Johannesburg, 21 Nov 2014.

[36] N. Kahiurika, "Landmark e-voting to go ahead in Namibia after court challenge fails", Mail \& Guardian news, 28 Nov 2014.

[37] J. K. Luo, "ECZ should introduce electronic voting", Zambia Daily Mail January 31, 2015.

[38] T. Chiripasi, "Observers Urge Zimbabwe to Introduce Electronic Voting", Voice of America | Zimbabwe news 10/01/2015.

[39] B. M. Munyati, "ERC urges e-voting for 2018", [Online].The Zimbabewan news, Available: http://www.the zimbabewan.co/news/Zimbabwenews/75020/.

[40] "Standing at a UK Parliamentary general election in Great Britain",
Available:http://www.electoralcommission.org.uk/ _data/assets/electoral_commission_pdf_file/0007/ 79540/UKPGE-nominations-factsheet-FINAL.pdf

[41] "Approved Guidelines and Regulations for the Conduct of 2015 General Elections", Independent National Electoral Commission, Nigeria.

[42] Voting in National Elections in Brazil,[Online]. Available: http://brazil.angloinfo.com/moving/voting/

[43] M. Achieng and E. Ruhode, "The Adoption and Challenges of Electronic Voting Technologies within the South African Context", International Journal of Managing Information Technology (IJMIT) Vol.5, No.4, November 2013

[44] D. Akinloye, Nigeria Elections 2015: “Corrupt INEC officials robbed APC of victory in Rivers' Lawmaker alleges", Pulse News, 18/04/2015,

[45] L. Okocha'Alleged corruption of INEC officials, threat to free poll' TODAY, [Online]. Available: https://www.today.ng/politics/108259/allegedcorruption-inec-officials-threat-free-poll, [Accessed: 07/05/2016]

[46] S. M. Abdulhamid, O. S, Adebayo, D. O. Ugiomoh, and M. D. AbdulMalik, "The Design and Development of Real-Time E-Voting System in Nigeria with Emphasis on Security and Result Veracity", I. J. Computer Network and Information Security, 2013, 5, 9-18.

[47] N. E. Obianyo and V. Emesibe, "Independent National Electoral Commission (INEC) and the Administration of 2015 Elections in Nigeria: The Strengths, the Weaknesses and the Challenges", Conference on The 2015 General Election in Nigeria: The Real Issues. Electoral Institute, Independent National Electoral Commission Abuja, July 26 - 29, 2015.

[48] L. E. Ebenezer, "A Synoptic Analysis of Issues in Nigerian Presidential Elections Disputes 1999 2007", Historical Research Letter, Vol.13, 2014,

[49] "Nigeria's Dangerous 2015 Elections: Limiting the Violence", International Crisis Group Working to Prevent Conflict Worldwide, 2015.

[50] Y. All, "160 killed in election related violence, say European monitors", The Nation, October 16, 2015.

[51] N. Ibeh, "58 Nigerians killed in 2015 pre-election violence so far - Rights Commission", Premium Times, February 13, 2015.

[52] M. Winsor," Nigeria Elections 2015 Considered 'Peaceful' Despite Rising Death Toll And Violence", International Business Times 04/09/2015,

[53] A. E. Ibor and J. N. Obidinnu "System Hardening Architecture for Safer Access to Critical Business Data Business Data", Nigerian Journal of Technology Vol. 34 No. 4, October 2015, pp. 788 - 792.

[54] N. David, "Design of an Internet Based Security System", Nigerian Journal of Technology Vol. 29 NO 2, June 2010. 